\title{
Analysis of Performance of V-CONE meter with experimentally and CFD
}

\author{
S. L. Patil, S. S. Sarawade \\ (Department of Mechanical Engineering, M.E.S. College of Engineering, Pune, S.P. Pune University, India)
}

\begin{abstract}
The measurement of fluid flow rate is important in many industrial applications like rocket propellant, petroleum industry, hydroelectricity station, water meter. Orifice, venturies meter, nozzles, venturi cones, venturi nozzles, drag plates are traditional flow rate measuring instruments. But, The V-Cone throttle device has been paid more and more attentions on the measurement of the wet gas flow in recent years. V-Cone flow meter has varies advantages over conventional flow meter. Finding out V-Cone Meter characteristics for measuring water flow rate is scope of this dissertation. In this research, beta ratio is considered between 0.55 to 0.85. By using volumetric flow equation, maximum diameter of V-Cone Meter is calculated for $102 \mathrm{~mm}$ diameter of pipe. Computational fluid dynamics (CFD) is used to simulate the flow in V-Cone Meter. Front angle and back angle of V-Cone Meter is optimized in ANSYS Fluent. Experimentation is held for different flow rate for finding flow rate constant $(\mathrm{Cd}) .0 .75$ is optimized beta ratio for flow rate between $125 \mathrm{~m} 3 / \mathrm{hr}$ to $60 \mathrm{~m} 3 / \mathrm{hr}$. experimentally flow rate constant is fluctuating between 0.8 to 0.87 for this V-Cone Meter. Experiments are carried out to validate the CFD predictions. This research is concluded that V-Cone Meter can also use for measuring water flow rate.
\end{abstract}

Key words-V-Cone Meter, beta ratio, CFD, water flow rate

\section{INTRODUCTION}

Water flow rate is important in industry like municipal water and wastewater, power, co-generation, mining, pulp-paper industry, industrial manufacturing, food, beverage. The V-Cone Meter provides flow measurement with an accuracy of up to $\pm 0.05 \%$ over a turn down ratio of 30:1 [1]. The pressure difference of front and back of the cone is used to realize flow speed measurement. V-Cone Meter expands the flow measurement scope and avoids some limitations of traditional difference flow meter. Velocity depends on the pressure differential that is forcing the fluid through a pipe. Because the pipe's cross-sectional area is known and remains constant, the average velocity is an indication of the flow rate. Other factors that affect liquid flow rate include the liquid's viscosity and density, and the friction of the liquid in contact with the pipe. Measurement of the flow of a fluid, either liquid or gas, is commonly a critical parameter in many processes. In most operations this can be linked to the basic need of the process, knowing that the right fluid is at the right place and the right time. Equally, it can be linked to asset management, keeping the fluid in motion or even simple tank balancing. Some applications, however, require the ability to conduct accurate flow measurements to such an extent that they influence product quality, health and safety, and ultimately can make the difference between making a profit and running at a loss. In Recent years many work is done with help of experimentally, numerically. Szabo, J.L., Winarski, C.P., Hypnar, P.R. [2] has compared the flow rate equations used for the VCone Meter with those defined by accepted standards for use with the square-edged orifice meter. Dr. RJW Peters, Dr. R. Steven [3], has reviewed V-Cone Meter experimentally by comparing with orifice meter. F Dong, C Tan, W Li, F S Zhang [4], a series of experiments of oil-water two-phase flows in a 50mm diameter Perspex horizontal pipe, the flow rates were measured with a V-Cone Meter flow meter with 0.65 diameter ratio. Weiguang Liu, Ying Xu, Tao Zhang, Fengfeng Qi [5], has compared V-Cone Meters of three different beta edge types with help of theoretical analysis, numerical simulations and experimental tests. Deng-Hui He, Bo-Feng Bai [6] demonstrate that the introduction of the Two-phase mass flow coefficient of the V-Cone throttle device makes a simple and accurate wet gas measurement correlation feasible. V.K. Singh, T. John Tharakan [7], have studied single- and multi-hole orifice meter over a wide range of Reynolds numbers with help of CFD. The discharge coefficient of multi-hole orifices is larger than that of single-hole orifice over a wide range of Reynold's numbers. It is challenge to find out performance of V-Cone Meter for measuring water flow rate. Whether V-Cone Meter characteristics change as fluid change, it is also a good research. For developing VCone Meter, Beta ratio and maximum diameter of V-Cone Meter is calculated by mathematical calculation. After getting fundamental dimension of V-Cone Meter, front and back angle is found by CFD software. Various combination of angles are analyze by keeping other parameter constant (e.g. beta ratio, flow rate, flow rate constant etc.). Ansys Fluent is used for numerical analysis. Various iterations are done to optimize angles. It also 
helps to reduce experimental cost and time. In this paper, V-Cone meter is designed to measure water flow rate in $100 \mathrm{NB}$ pipe. Flow rate constant $\left(\mathrm{C}_{\mathrm{d}}\right)$ is found out by numerical and experimental method.

\section{V-CONE METER}

From Fig. 1 [5], it can be seen that the V-Cone Meter upstream tapping is on the wall of the pipe but the downstream tapping is not on the wall of the pipe but on the back face of the cone on the pipe center line. This is a radical departure from the traditional DP meter designs and this design gives some significant performance improvements which will be discussed in chapter two. The different geometry can cause some engineers to wonder if the V-Cone Meter operates according to a different principle than the traditional DP meters but this is not so. The governing flow equation for the V-Cone is identical to that of all other DP meters. From the users point of view all secondary equipment used is exactly the same as would be chosen for any DP meter. That is the same manifolds, DP transmitters and Flow Computers are used as are used with other DP meters(with the flow computer requiring the $\mathrm{V}$-cone equation just as it requires the unique equation for any DP meter).Therefore use of a V-Cone Meter requires no further understanding than that knowledge required to use any other DP meter.

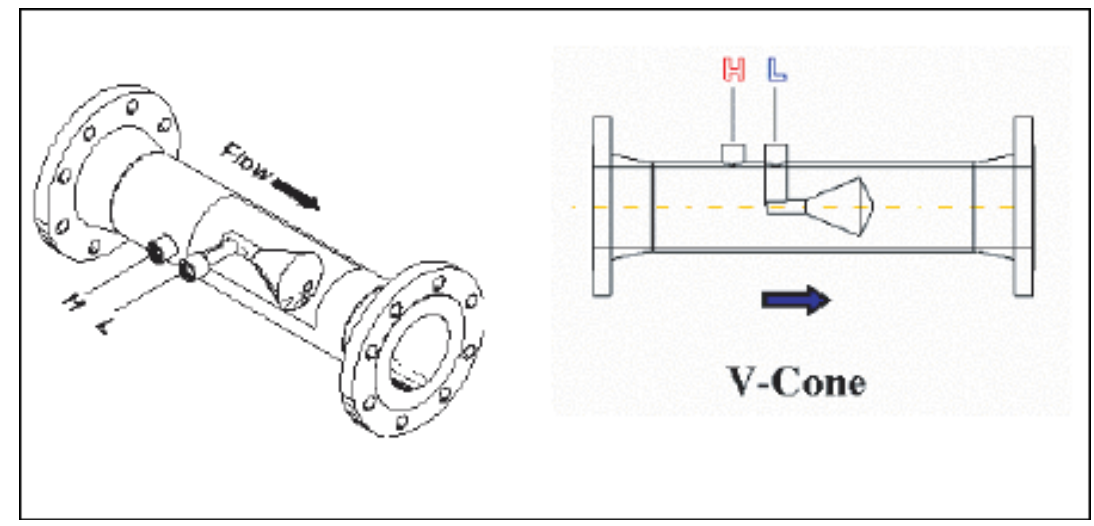

Fig. 1. General V-Cone Meter 3D View and Flow Direction

All DP meters work according to the principles of the conservation of mass and energy. Depending on specific DP meter geometries, some of the parameters are calculated in different ways. In V-Cone Meter, water is flowing along wall of pipe (peripheral side) and in orifice meter, water is flowing from center part of pipe (As shown in Fig 2) [4]. Due to the different geometry the V-Cone Meter beta ratio is calculated by equation 1. Where $\mathrm{A}$ is the upstream pipe cross sectional area, $\mathrm{d}$ inner diameter of orifice, $\mathrm{D}$ is the upstream pipe diameter and $\mathrm{dc}$ is the cone diameter.

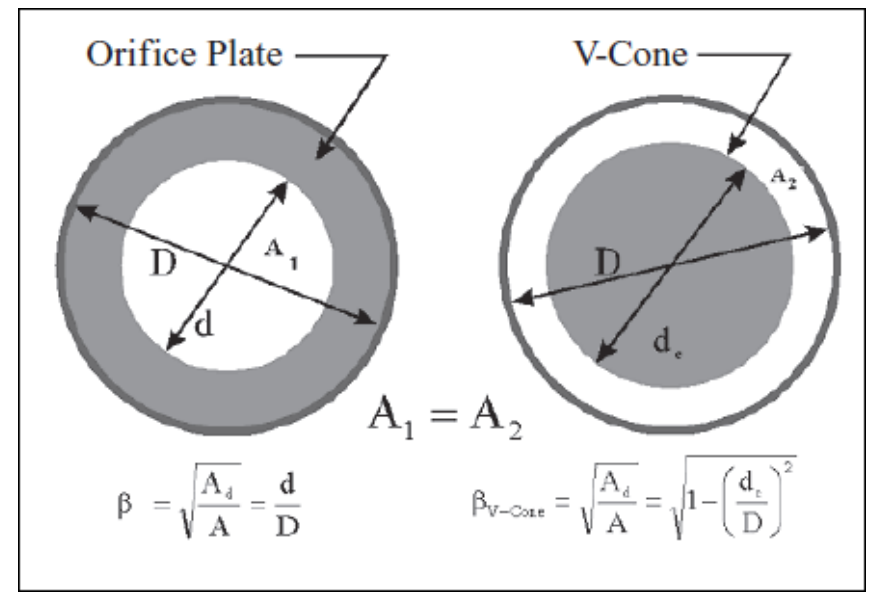

Fig. 2. Schematic Diagram of Orifice Plate and C-cone meter for Beta Ratio Calculation

$\beta_{\text {Traditinal }}=\sqrt{\frac{A_{d}}{A}}=\frac{d}{D}$ 


$$
\beta_{V-\text { cone }}=\sqrt{\frac{A_{d}}{A}}=\sqrt{1-\left(\frac{d_{c}}{D}\right)^{2}}
$$

\section{A. Volumetric Flow Calculation}

Volumetric flow rate equation (eq.2) [7] is basic equation to calculate beta ratio of V-Cone Meter at flowing conditions.

$$
q_{v}=N_{v p} x \frac{C \cdot \beta_{\text {fvcone }}^{2} \cdot D^{2}}{\sqrt{1-\beta_{\text {fvone }}^{4}}} x \frac{1}{\sqrt{F_{p} \cdot \rho_{f}}} x \sqrt{\Delta P}
$$

Dimensions of pipe from which fluid is flowing change with flowing conditions. Dimensions of pipes are affected by temperature specially (Eq.4).

$D=\left[1+\alpha_{p}(T-20)\right] D_{i}$

Beta ratio is very important element of any flow meter. But equation of beta ratio is different for V-Cone Meter is different than orifice and venturi meter. [11]

To summarize V-Cone Meter, finding out its characteristic for specific application.

Water as fluid, Pipe diameter $=100 \mathrm{~N}$, Inner diameter of pipe, $\mathrm{Di}=102.26 \mathrm{~mm}$, Beta ratio $=0.75$, Operating temperature $=27-35^{\circ} \mathrm{C}$, Density at operating temperature $=996 \mathrm{~kg} / \mathrm{m}^{3}$.

From Eq.2, Maximum diameter of V-Cone Meter is $67.6 \mathrm{~mm}$

\begin{tabular}{|c|c|c|c|c|c|}
\hline ID & D & qv & Delta P & Delta p & $\mathrm{d}$ (fvcone) \\
\hline 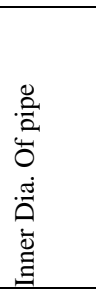 & 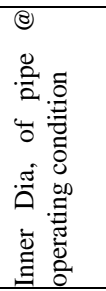 & 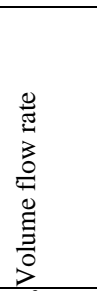 & 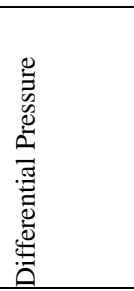 & 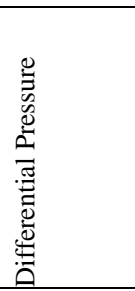 & 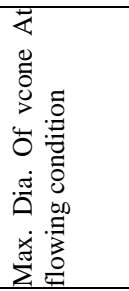 \\
\hline $\mathrm{mm}$ & $\mathrm{mm}$ & $\mathrm{m}^{3} / \mathrm{hr}$ & $\mathrm{kPa}$ & $\mathrm{mmWC}$ & $\mathrm{mm}$ \\
\hline 102.26 & 102.272 & 125.49 & 24.587992 & 2507.2376 & 67.6 \\
\hline 102.26 & 102.272 & 125.33 & 24.525333 & 2500.8482 & 67.6 \\
\hline 102.26 & 102.272 & 125.31 & 24.517506 & 2500.0501 & 67.6 \\
\hline 102.26 & 102.272 & 116.03 & 21.020615 & 2143.4721 & 67.6 \\
\hline 102.26 & 102.272 & 115.33 & 20.767748 & 2117.6873 & 67.6 \\
\hline 102.26 & 102.272 & 100.09 & 15.641781 & 1594.9925 & 67.6 \\
\hline 102.26 & 102.272 & 99.76 & 15.538808 & 1584.4923 & 67.6 \\
\hline 102.26 & 102.272 & 88.73 & 12.292658 & 1253.4823 & 67.6 \\
\hline 102.26 & 102.272 & 88.66 & 12.27327 & 1251.5053 & 67.6 \\
\hline 102.26 & 102.272 & 72.74 & 8.2613577 & 842.41065 & 67.6 \\
\hline 102.26 & 102.272 & 72.55 & 8.2182560 & 838.01557 & 67.6 \\
\hline 102.26 & 102.272 & 60.12 & 5.6434252 & 575.46008 & 67.6 \\
\hline 102.26 & 102.272 & 60.1 & 5.6396711 & 575.07726 & 67.6 \\
\hline
\end{tabular}

Table 1. Theoretical Differential Pressure for Different Flow Rate for $\mathrm{Cd}=0.85$

As shown in Table 1, Differential pressure is directly proportional to flow rate. Practically, differential pressure is measured in millimeter water column ( $\mathrm{mmWC}$ ) in this experimental set up. So at the time of experimentation $\mathrm{DP}$ value in $\mathrm{mmWC}$ are required. Conversion is $1 \mathrm{kPa}=101.971 \mathrm{mmWC}$. 


\section{NUMERICAL ANALYSIS OF V-CONE METER WITH ANSYS FLUENT 14.0}

From beta ratio equation (1), max. Diameter of V-Cone Meter is $67.6 \mathrm{~mm}$. Solid model of V-Cone Meter is prepared in CATIA software (As shown in Fig. 3). As shown in Fig. 4, all important dimensions of VCone Meter are displayed. Angle $\varnothing 1$ and Angle $\varnothing 2$ are unknown parameters which are finding out by number of iterations in CFD.

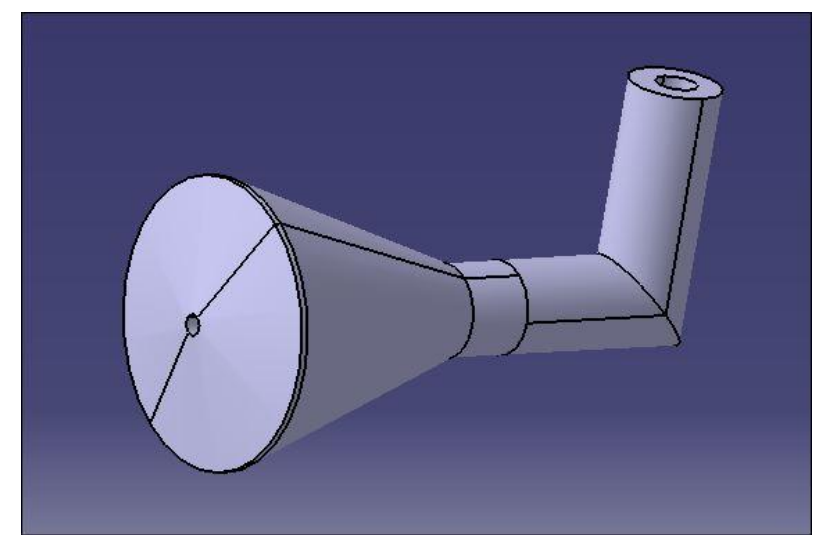

Fig. 3. CAD Model of V-Cone Meter in CATIA V5

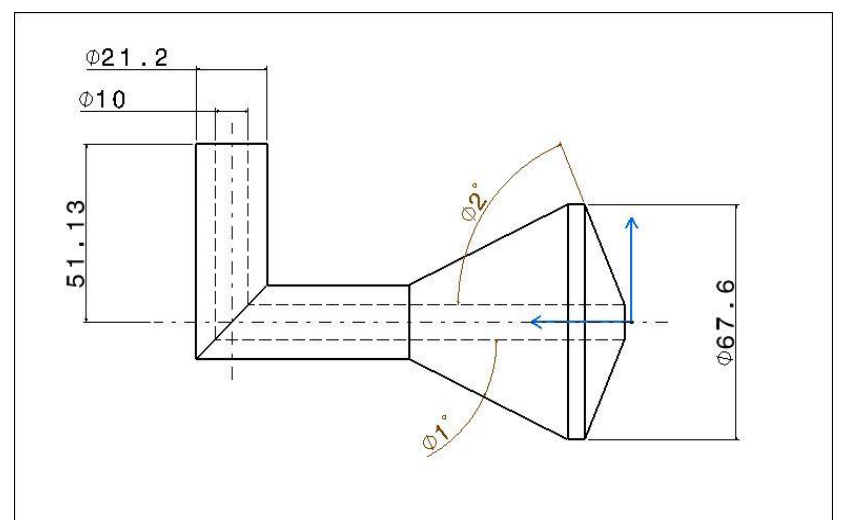

Fig 4. Important Dimensions of V-Cone Meter (all dimensions in mm)

Behavior of water flow is analyzed by Computational fluid dynamics (CFD) in ANSYS FLUENT 14.0. Pressure based solver and Realizable k- $\varepsilon$ (RKE) model is suitable for V-Cone Meter analysis. With Boolean operation water domain is prepared in ANSYS. All water domain is meshed with TETRA elements (number of elements 386526). After applying all boundary conditions and initial values, differential pressure (DP) are got for different flow rate.As mentioned in Table 2, differential pressure is decrease as flow rate is decrease. As shown in Table 3, angles of V-Cone Meter is make impact on DP. As angle changes, behavior of V-Cone Meter is also changed. After comparing Numerical DP with theoretical DP, DP of V-Cone Meter with angle $20^{\circ}$ and $80^{\circ}$ are more close to theoretical value. So, angle $20^{\circ}$ and $80^{\circ}$ are selected for further calculations.

Table 2. DP value for actual flow rate value From CFD software.

\begin{tabular}{|l|l|l|l|}
\hline Flow Rate & Flow Rate & Velocity & Numerical (CFD) DP \\
\hline $\mathrm{m}^{3} / \mathrm{hr}$ & $\mathrm{kg} / \mathrm{s}$ & $\mathrm{m} / \mathrm{s}$ & Pascal \\
\hline 125.49 & 34.72 & 4.24 & 20665.56 \\
\hline 125.33 & 34.67 & 4.24 & 20452.56 \\
\hline 125.31 & 34.67 & 4.24 & 20500.96 \\
\hline 116.03 & 32.10 & 3.92 & 17551.80 \\
\hline 115.33 & 31.91 & 3.90 & 17368.10 \\
\hline 100.09 & 27.69 & 3.38 & 13700.16 \\
\hline 99.76 & 27.60 & 3.37 & 13281.59 \\
\hline 88.73 & 24.55 & 3.00 & 10552.81 \\
\hline 88.66 & 24.53 & 3.00 & 10536.83 \\
\hline 72.74 & 20.12 & 2.46 & 7271.60 \\
\hline 72.55 & 20.07 & 2.45 & 7249.60 \\
\hline 60.12 & 16.63 & 2.03 & 5214.10 \\
\hline 60.1 & 16.63 & 2.03 & 5214.30 \\
\hline
\end{tabular}


Table 3. Effect of V-Cone Meter Angle on DP

\begin{tabular}{|c|c|c|c|c|}
\hline \multicolumn{2}{|c|}{ Flow rate in $\mathrm{m}^{3} / \mathrm{hr}$} & 115 & 100 & 90 \\
\hline Angle $\varnothing 1$ & Angle $\varnothing 2$ & \multicolumn{3}{|c|}{ Differential Pressure (DP) in CFD (Pa) } \\
\hline 25 & 75 & 17205 & 12708 & 10317 \\
\hline 15 & 75 & 8611 & 6430 & 5265 \\
\hline 26 & 67.5 & 15675 & 12046 & 9550 \\
\hline 20 & 80 & 17739 & 13414 & 10821 \\
\hline \multicolumn{2}{|c|}{ Theoretical Differential Pressure (DP) (Pa) } & 20650 & 15613 & 12647 \\
\hline
\end{tabular}

\section{EXPERIMENTAL ANALYSIS OF V-CONE METER}

To find out actual effect of V-Cone Meter on DP, experimental analysis is done under actual conditions.

Components of experimental set up (Fig.5) [16]:
1. Constant Head Tank (20 m3)
8. $\quad$ Control (Butterfly) Valve
2. Butterfly Valve
9. Diverter
3. Pressure Transmitter
10. Weigh Tank $(5000 \mathrm{~kg})$
4. Temperature Transmitter
5. Conditioning Flow Meter
11. Weigh Bridge
6. Flow Meter To Be Calibrated
12. Water Reservoir
7. DP Transmitter
13. Overflow Return Line
14. Low Pressure Pump (3 nos.)

Calculation for flow rate after experimentation.

\section{Calculation of actual flow rate $\left(Q_{a}\right)$}

$Q_{a}=\frac{M * 3600}{\rho * t}$

$\mathrm{Q}_{\mathrm{a}}$ is in $\mathrm{m}^{3} / \mathrm{hr}$

$\mathrm{M}=$ Mass of water flow through pipe in $\mathrm{tsec}, \mathrm{Kg}$

$\mathrm{t}=$ time, second

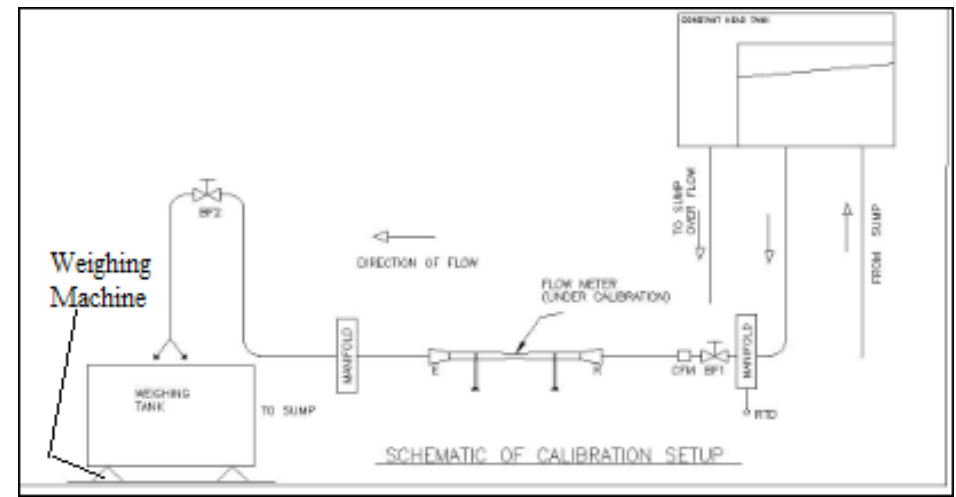

Fig. 5. Water Flow Direction in Testing Setup

2. Calculation of theoretical flow $\left(Q_{t}\right)$

$Q_{t}=A * \sqrt{\frac{2 * \Delta P}{\left(1-\beta^{4}\right)^{*} \rho}}$

$\mathrm{A}=$ Area through which water is flowing, $\mathrm{m}^{2}$

3. V-cone flow meter constant $\left(\mathrm{C}_{\mathrm{d}}\right)$

$C_{d}=\frac{Q_{a}}{Q_{t}}$

Table 4. Experimental Differential Pressure (DP) Value

\begin{tabular}{|l|l|l|l|c|c|}
\hline Mass of Water & Time & DP & Actual Flow & Theoretical Flow & Flow meter Constant \\
\hline$K g$ & Sec & Pascal & $\mathrm{m}^{3} / \mathrm{hr}$ & $\mathrm{m}^{3} / \mathrm{hr}$ & \\
\hline 1314 & 37.901 & 22905.96 & 125.31 & 141.815 & 0.883 \\
\hline 1305 & 37.66 & 22923.35 & 125.24 & 141.87 & 0.882 \\
\hline 1350 & 38.99 & 22907.5 & 125.19 & 141.82 & 0.882 \\
\hline 1396 & 40.207 & 22888.97 & 125.49 & 141.76 & 0.885 \\
\hline 1398 & 40.181 & 22901.944 & 125.23 & 141.8 & 0.883 \\
\hline
\end{tabular}


Analysis of Performance of V-CONE Meter with Experimentally and CFD

\begin{tabular}{|l|l|l|l|l|l|}
\hline 1393 & 37.293 & 22929.75 & 125.33 & 141.89 & 0.883 \\
\hline 1190 & 35.726 & 19531.44 & 115.33 & 130.95 & 0.88 \\
\hline 1140 & 38.856 & 19577.8 & 116.03 & 131.5 & 0.882 \\
\hline 1072.5 & 39.199 & 14737.11 & 99.76 & 113.75 & 0.877 \\
\hline 1085 & 42.85 & 14816.81 & 100.09 & 114.05 & 0.877 \\
\hline 1052 & 38.971 & 11781.9 & 88.73 & 101.70 & 0.872 \\
\hline 956 & 44.634 & 11763.37 & 88.66 & 101.62 & 0.872 \\
\hline 896 & 44.373 & 7994.27 & 72.55 & 83.78 & 0.866 \\
\hline 893 & 42.754 & 8014.66 & 72.74 & 83.88 & 0.867 \\
\hline 860 & 42.754 & 7955.33 & 72.7 & 83.57 & 0.869 \\
\hline 777 & 46.722 & 5773.22 & 60.1 & 71.19 & 0.844 \\
\hline 829 & 49.869 & 5773.19 & 60.12 & 71.19 & 0.844 \\
\hline
\end{tabular}

From equations 4, 5, 6 and experimental readings, flow rate constant is calculated. As in table 3 , there is difference in actual DP and theoretical DP. Flow meter constant value $\left(\mathrm{C}_{\mathrm{d}}\right)$ is approximately 0.85 for this VCone Meter.

\section{RESULTS}

V-Cone Meter is analyzed by theoretical, numerical (CFD) and experimental methods. Differential pressure (DP) is determined for different flow rates in three different way (as shown in Table 5). Flow rate is changed from $130 \mathrm{~m}^{3} / \mathrm{hr}$ to $60 \mathrm{~m}^{3} / \mathrm{hr}$ range. After all calculations and testing, theoretical results are considered as datum. CFD simulation shows lower values than other analysis. Theoretical DP is higher at same flow rate. (As shown in Fig.6).

Table 5. Comparison of Theoretical, Numerical, Experimental DP

\begin{tabular}{|c|c|c|c|c|c|c|}
\hline 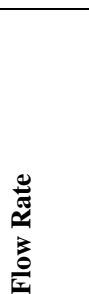 & 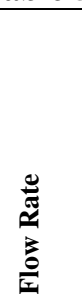 & 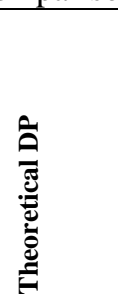 & 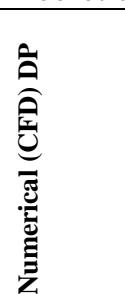 & 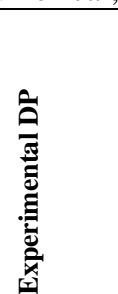 & 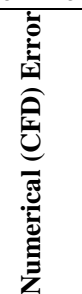 & 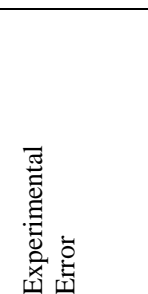 \\
\hline $\mathrm{m}^{3} / \mathrm{hr}$ & $\mathrm{kg} / \mathrm{s}$ & \multicolumn{3}{|l|}{ Pascal } & \multicolumn{2}{|c|}{$\%$ w.r.t. Theoretical DP } \\
\hline 125.49 & 34.72 & 24587.99 & 20665.56 & 22905.65 & 15.95 & 6.84 \\
\hline 125.33 & 34.67 & 24525.33 & 20452.56 & 22923.35 & 16.61 & 6.53 \\
\hline 125.31 & 34.67 & 24517.51 & 20500.96 & 22907.51 & 16.38 & 6.57 \\
\hline 116.03 & 32.10 & 21020.62 & 17551.80 & 20010.45 & 16.50 & 4.81 \\
\hline 115.33 & 31.91 & 20767.74 & 17368.10 & 19531.44 & 16.37 & 5.95 \\
\hline 100.09 & 27.69 & 15641.78 & 13700.16 & 14816.83 & 12.41 & 5.27 \\
\hline 99.76 & 27.60 & 15538.80 & 13281.59 & 14737.11 & 14.53 & 5.16 \\
\hline 88.73 & 24.55 & 12292.65 & 10552.81 & 11763.90 & 14.15 & 4.30 \\
\hline 88.66 & 24.53 & 12273.27 & 10536.83 & 11763.37 & 14.15 & 4.15 \\
\hline 72.74 & 20.12 & 8261.35 & 7271.60 & 7994.27 & 11.98 & 3.23 \\
\hline 72.55 & 20.07 & 8218.25 & 7249.60 & 7955.33 & 11.79 & 3.20 \\
\hline 60.12 & 16.63 & 5643.42 & 5214.10 & 5773.22 & 7.61 & -2.30 \\
\hline 60.1 & 16.63 & 5639.67 & 5214.30 & 5773.19 & 7.54 & -2.37 \\
\hline
\end{tabular}

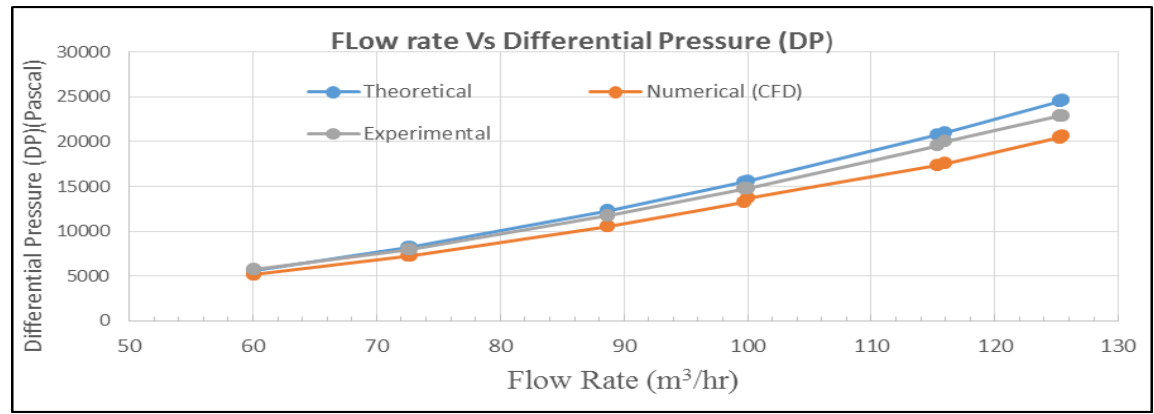

Fig. 6. Flow Rate Vs Differential Pressure (DP)

Theoretical differential pressure, Numerical (CFD) differential pressure and experimental differential pressure (DP) are close for given flow rate. 


\section{CONCLUSIONS}

Optimized geometry of V-Cone Meter is developed to measure water flow. With help of ANSYS FLUENT (CFD) optimized cone angles are found. i.e. $\theta 1=20^{\circ}$ and $\theta 2=80^{\circ}$. V-Cone Meter shows considerable changes in differential pressure (DP) according to change in water flow. Optimized beta ratio of V-Cone Meter is 0.75 for given requirements ( $100 \mathrm{NB}$ pipe diameter, $1.44 \mathrm{bar}$ input pressure, $130 \mathrm{~m}^{3} / \mathrm{hr}-90 \mathrm{~m}^{3} / \mathrm{hr}$ water flow). V-Cone Meter shows good results for measuring water flow rate. Theoretical differential pressure, Numerical (CFD) differential pressure and experimental differential pressure (DP) are matching farely well, some error is due to frictional losses and measuring instruments error. For V-Cone Meter, flow meter constant (Cd) for is constant. From above conclusions, V-Cone Meter can replace traditional DP flow meter (like orifice meter, venturi meter etc.) for measuring water flow rate.

\section{REFERENCES}

[1] W.Zhu, J. Meng, Z.Yin, 3-D Numerical Simulation And Analysis On V-Cone Flowmeter Based On LES Method, Applied Mechanics And Materials, Trans Tech Publications, Switzerland, Online: 2011-08-22, ISSN: 1662-7482, 8889, 408-412.

[2] J.L .Szabo, C.P .Winarski,P.R. Hypnar, A Review of the V-Cone Meter for Natural Gas Flows, Omae Calgary, Alberta, June 7-11th, 1992.

[3] RJW Peters, R. Steven, An Overview of the Micrometer V-Cone Meter American School of Gas Measurement Technology 2003, 3255 w, STETSON AVE., HEMET, CA,92545-7799.

[4] F. Dong, C Tan, W Li, F S Zhang, Flow Rate Measurement of Oil-Water Two-Phase Flow Based on V-Cone Meter Flow Meter, 6th International Symposium on Measurement Techniques for Multiphase Flows, Flows IOP Publishing, Journal of Physics: Conference Series 147,2009, 012059 doi:10.1088/1742-6596/147/1/012059.

[5] W. Liu, Ying Xu, Tao Zhang, Fengfeng Qi, Performance Measurement Analysis of Various Cone Flow Meters With Various Beta Edge Types and Flow Field Parameters, Flow Measurement and Instrumentation, Elsevier, 45,2015 ,331-340.

[6] Deng-Hui He, Bo-Feng Bai, Two-Phase Mass Flow Coefficient of V-Cone Meter Throttle Device, Published by Elsevier Inc., Experimental Thermal and Fluid Science, 57 (2014) 77-85, 16 April 2014.

[7] V.K. Singh, T. John Tharakan, Numerical Simulations for Multi-Hole Orifice Flow Meter, Flow Measurement and Instrumentation, Elsevier, 45 (2015) 375-383, 18 August 2015.

[8] Shailesh Patil, Dr. S. S. Sarawade, Design of V-Cone Meter to Measure Water Flow, 5th National Conference RDME 2016, IOSR Journal of Mechanical \& Civil Engineering, ISSN (e):2278-1684, ISSN (p): 2320-334, 10-11th March 2016.

[9] Shailesh Patil, Dr. S.S.Sarawade, Analyze Performance of V-Cone Meter by Experimentally and Theoretically, MECH PGCON 2016

[10] R.K. Bansal, Fluid Mechanics and Hydraulic Machines, (Laxmi publication, $9^{\text {th }}$ edition, 2005).

[11] Richard W. Miller, Flow Measurement Engineering Handbook,( New York: McGraw-Hill, 1996).

[12] BS1042: Measurement of Fluid Flow in Closed Conduits, Section 1.1, 1.2, 1.4, 1.5, 1981.

[13] Manual, Star-Mech Controls (I) Pvt. Ltd., Pune.

[14] Advanced Differential Pressure Flowmeter Technology, (3255 West Stetson Avenue, Hemet, California, USA).

[15] http://www.starmech.net/index.html

[16] https://confluence.cornell.edu/display/SIMULATION/FLUENT+Learning+Modules. 